\title{
Comments to Metallothionein as an Anti-Inflammatory Mediator
}

\author{
Yong-Song Guan \\ Department of Oncology, State Key Laboratory of Biotherapy, West China Hospital of Sichuan University, P.O. Box 610041, \\ Guoxuexiang Street 37, 61004 Chengdu, Sichuan, China
}

Correspondence should be addressed to Yong-Song Guan, yongsongguan@yahoo.com

Received 14 July 2009; Accepted 7 September 2009

Copyright (C) 2009 Yong-Song Guan. This is an open access article distributed under the Creative Commons Attribution License, which permits unrestricted use, distribution, and reproduction in any medium, provided the original work is properly cited.

Dear Editor,

This paper introduces MTs as metalloproteins and their role in various inflammatory diseases. In the conclusion section, the authors state that MT-induction/enhancement and/or zinc supplementation to induce/enhance MT might be possible therapeutic options for inflammatory diseases [1].

To be an appropriate therapy on the level of genetics or molecule, the option should be well meditated because the targeting network for a cellular process is so complicated. First do no harm, which is the foremost principle for a therapy [2]. However, there is scarce any medical good without its concomitant harm. For example, it is reported that antibiotic treatment of bacterial infection, even if being successful, hinders development of acquired immunity so that the immune responses of the host confer no protection to secondary infection [3]. Anyway, the proposal for a therapeutic option needs discretion.

Unfortunately, inflammation events and evidence provided in this paper are not sufficient enough to support MT as an anti-inflammatory mediator. Traumatic injury is not the mainstay of inflammatory diseases, and restrained inflammation is regarded as beneficial for host wound healing and defense toward infection [4]. Acute liver injury has quite different pathophysiology compared to viral hepatitis, liver cirrhosis, and liver cancer, which are chronic. Mechanism of anti-inflammatory mediation needs clearer presentation.

Both MT and zinc are tightly regulated in the body. Zinc is crucial for the activation and binding of certain transcription factors through the participation in the zinc finger region of MT. Thus, MT regulates the level of zinc by binding and releasing this essential trace element. Too much zinc is also harmful to the body with resultant intoxication
[5]. Surplus zinc is captured by MT the same as it detoxifies other heavy metals by forming inclusions and crystals $[6,7]$.

Simply inducing or enhancing MT is harmful because both increased and decreased expression of MT lead to malignant transformation of cells and ultimately cancer [8]. The former is found in several cancers including that of the breast, colon, and prostate, while the latter is detected in liver cancer [9]. In addition, higher levels of MT expression have proved to result in chemoresistance to drugs [10].

I would suggest fine tuning rather than sole induction or enhancement of MT, discussing one particular inflammatory disease instead of generalized ones, and investigating the effects of both increased and decreased MT expression with emphasis on the homeostasis of this mediator. In addition, zinc supplementation is indicated to zinc deficiency not to inflammation.

Yong-Song Guan

\section{References}

[1] K. Inoue, H. Takano, A. Shimada, and M. Satoh, "Metallothionein as an anti-inflammatory mediator," Mediators of Inflammation, vol. 2009, Article ID 101659, 7 pages, 2009.

[2] X. Zhang, "Ethical reflection on human gene therapy in the Chinese context," International Journal of Bioethics, vol. 19, no. 4, pp. 95-104, 163, 2008.

[3] A. Griffin, D. Baraho-Hassan, and S. J. McSorley, "Successful treatment of bacterial infection hinders development of acquired immunity," The Journal of Immunology. In press.

[4] T. Glaros, M. Larsen, and L. Li, "Macrophages and fibroblasts during inflammation, tissue damage and organ injury," Frontiers in Bioscience, vol. 14, pp. 3988-3993, 2009. 
[5] S. Pawa, A. J. Khalifa, M. N. Ehrinpreis, C. A. Schiffer, and F. A. Siddiqui, "Zinc toxicity from massive and prolonged coin ingestion in an adult," American Journal of the Medical Sciences, vol. 336, no. 5, pp. 430-433, 2008.

[6] G. P. Borrelly, M. D. Harrison, A. K. Robinson, S. G. Cox, N. J. Robinson, and S. K. Whitehall, "Surplus zinc is handled by Zyml metallothionein and Zhf endoplasmic reticulum transporter in Schizosaccharomyces pombe," Journal of Biological Chemistry, vol. 277, no. 33, pp. 30394-30400, 2002.

[7] H. C. Chiang, J. C. Lo, and K. C. Yeh, "Genes associated with heavy metal tolerance and accumulation in $\mathrm{Zn} / \mathrm{Cd}$ hyperaccumulator Arabidopsis halleri: a genomic survey with cDNA microarray," Environmental Science and Technology, vol. 40, no. 21, pp. 6792-6798, 2006.

[8] S. Krizkova, I. Fabrik, V. Adam, J. Hrabeta, T. Eckschlager, and R. Kizek, "Metallothionein-a promising tool for cancer diagnostics," Bratisl Lek Listy, vol. 110, no. 2, pp. 93-97, 2009.

[9] J. Datta, S. Majumder, H. Kutay, et al., "Metallothionein expression is suppressed in primary human hepatocellular carcinomas and is mediated through inactivation of CCAAT/enhancer binding protein $\alpha$ by phosphatidylinositol 3-kinase signaling cascade," Cancer Research, vol. 67, no. 6, pp. 2736-2746, 2007.

[10] X. Yap, H. Y. Tan, J. Huang, et al., "Over-expression of metallothionein predicts chemoresistance in breast cancer," Journal of Pathology, vol. 217, no. 4, pp. 563-570, 2009. 


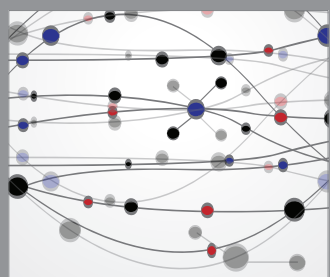

The Scientific World Journal
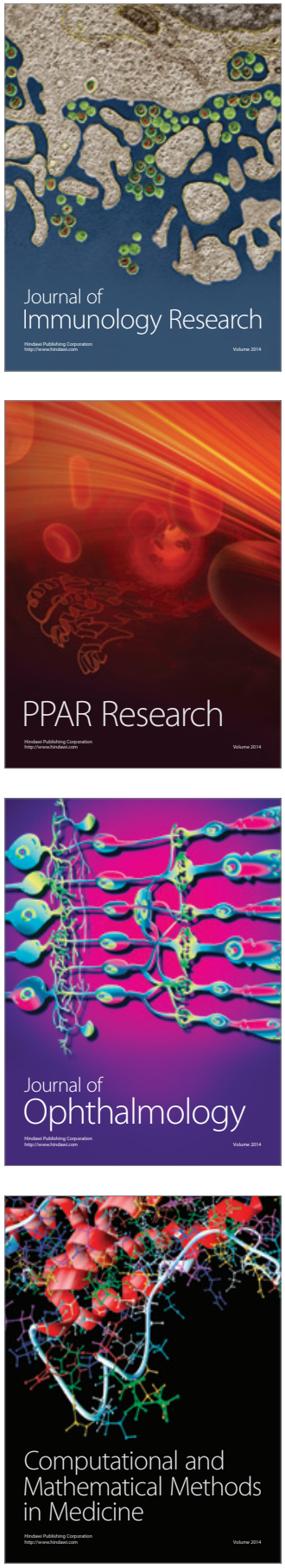

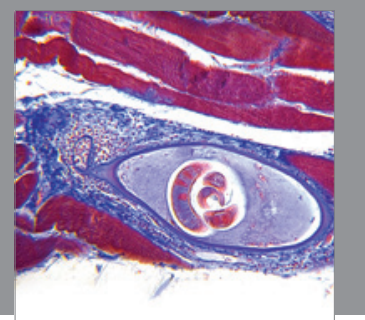

Gastroenterology

Research and Practice
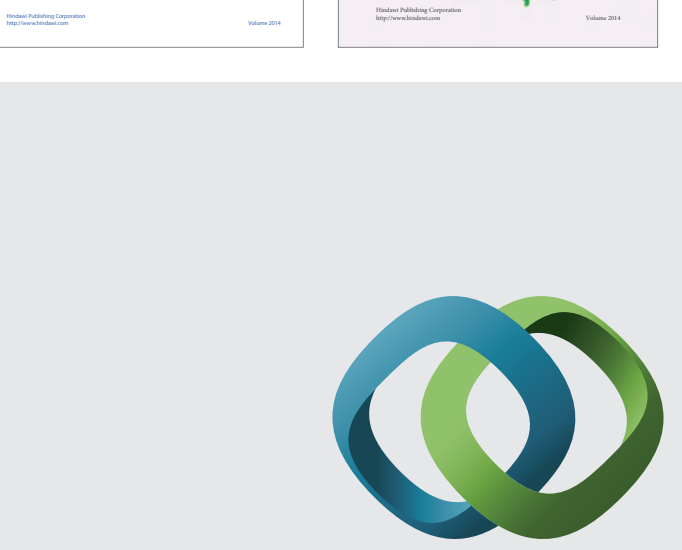

\section{Hindawi}

Submit your manuscripts at

http://www.hindawi.com
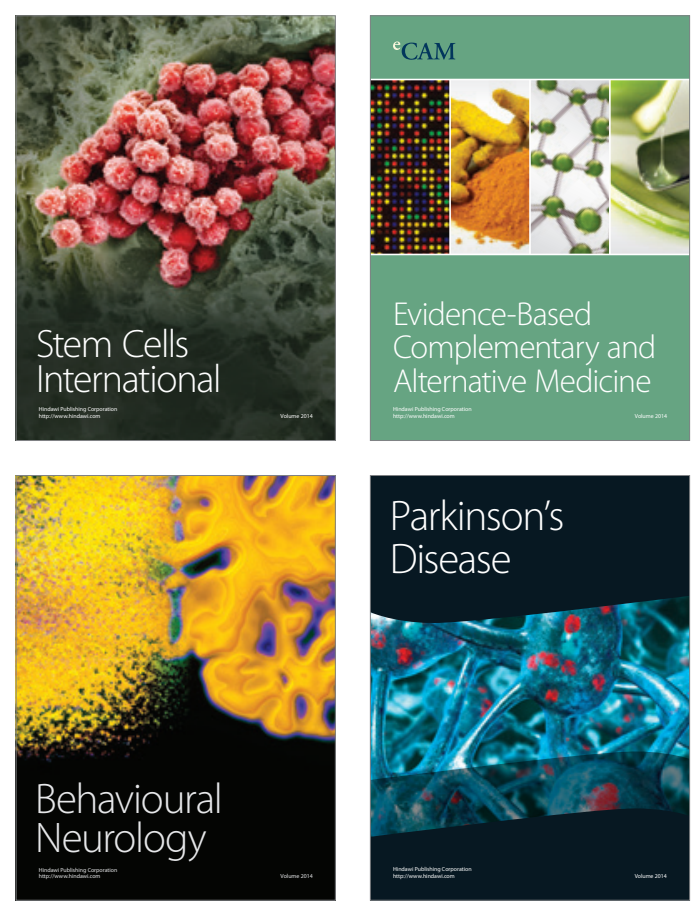

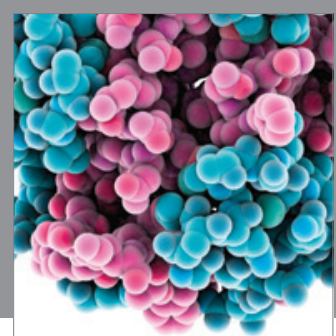

Journal of
Diabetes Research

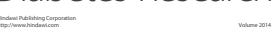

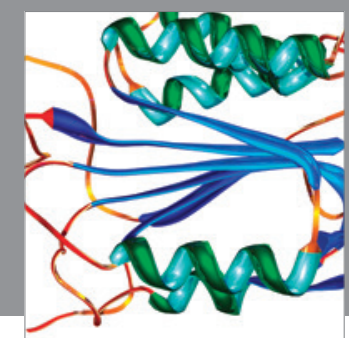

Disease Markers
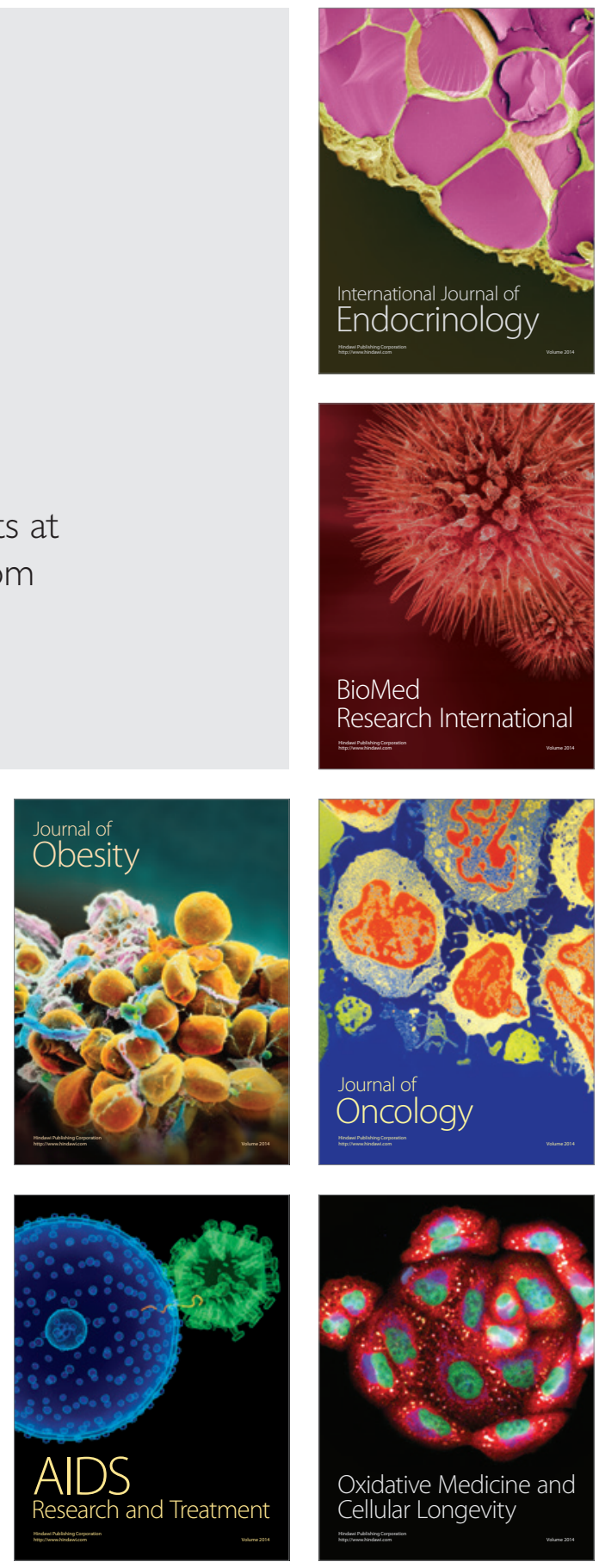